\title{
Beneficial effects of hydrogen gas inhalation on a murine model of allergic rhinitis
}

\author{
SHENGJIAN FANG $^{1 *}$, XINQIAN LI ${ }^{1 *}$, XIAN WEI $^{1}$, YU ZHANG $^{1}$, \\ ZHAOXIN MA $^{1}$, YOUZHEN WEI ${ }^{2,3}$ and WEIHUA WANG ${ }^{1}$ \\ ${ }^{1}$ Department of Otolaryngology-Head and Neck Surgery; ${ }^{2}$ Research Center for Translational Medicine, \\ Shanghai East Hospital; ${ }^{3}$ Key Laboratory of Arrhythmias of The Ministry of Education of China, \\ Tongji University School of Medicine, Shanghai 200120, P.R. China
}

Received April 17, 2018; Accepted September 24, 2018

DOI: $10.3892 /$ etm.2018.6880

\begin{abstract}
Allergic rhinitis (AR) is a common chronic inflammatory condition. It has been previously indicated that oxidative stress may contribute to allergic inflammation, including AR. Although molecular hydrogen $\left(\mathrm{H}_{2}\right)$, an antioxidative agent, has been effective in treatment of numerous oxidative stress-associated diseases, the effect of inhalation of a high concentration of $\mathrm{H}_{2}$ on $\mathrm{AR}$ remains unknown. In the current study, female BALB/c mice were sensitized with ovalbumin (OVA) followed by intranasal OVA challenge to establish an animal model of AR. Mice were subjected to exposure to $\mathrm{H}_{2}$ and the inert gas helium at different frequencies and durations. The frequencies of sneezing/scratching and the body weights of mice were recorded. Histological analysis and multiplex cytokine assays were performed to evaluate the effects of $\mathrm{H}_{2}$ on AR. Challenge with OVA induced significant nasal mucosa inflammation. $\mathrm{H}_{2}$ inhalation reduced the infiltration of inflammatory cells into mucosa and lowered the levels of interleukin (IL)-5, IL-13 and monocyte chemoattractant protein-1 in serum. $\mathrm{H}_{2}$ inhalation slightly increased the level of interferon- $\gamma$, however the difference was not statistically
\end{abstract}

Correspondence to: Dr Youzhen Wei, Research Center for Translational Medicine, Shanghai East Hospital, Tongji University School of Medicine, 150 Jimo Road, Shanghai 200120, P.R. China E-mail: weiyouzhen062014@163.com

Dr Weihua Wang, Department of Otolaryngology-Head and Neck Surgery, Shanghai East Hospital, Tongji University School of Medicine, 150 Jimo Road, Shanghai 200120, P.R. China

E-mail: whwangcn@outlook.com

*Contributed equally

Abbreviations: AR, allergic rhinitis; IgE, immunoglobulin E; IL-5, interleukin-5; IL-13, interleukin-13; IFN- $\gamma$, interferon- $\gamma$; MCP-1, monocyte chemoattractant protein-1; NS, normal saline; OVA, ovalbumin; ROS, reactive oxygen species

Key words: allergic rhinitis, hydrogen, ovalbumin, cytokine, chemokine, weight control significant. Treatment with $\mathrm{H}_{2}$ limited the weight increase in healthy mice and reversed the weight loss in mice with AR. Furthermore, $\mathrm{H}_{2}$ inhalation induced a therapeutic effect on $\mathrm{AR}$ in a dose-dependent manner. The current results demonstrate that $\mathrm{H}_{2}$ may demonstrate a therapeutic value for allergic diseases.

\section{Introduction}

Allergic rhinitis (AR) is a common chronic inflammatory condition of the upper airways that affects $10-40 \%$ of the global population $(1,2)$. In China, it has been reported that $8.7-24.1 \%$ of the population suffers from AR (3). The differences in incidence may be due to region-specific environmental conditions. As a major public health problem, AR affects the quality of life, and imposes a financial and social burden (4). The current therapeutic strategies for AR include allergen avoidance, symptomatic pharmacotherapy and allergen-specific immunotherapy (5). While these strategies are effective, the majority of them require lifelong use and have a number of side effects (4). These medications, such as nasal decongestants, H1-antihistamines, and nasal corticosteroids can relieve nasal symptoms, although not completely, in a considerable number of patients (4).

An increasing number of studies have indicated that molecular hydrogen $\left(\mathrm{H}_{2}\right)$ induces beneficial effects in numerous oxidative stress-associated diseases (6-17). It has been demonstrated that oxidative stress contributes to allergic inflammation, including asthma and AR (6-8). As an antioxidative agent, $\mathrm{H}_{2}$ mediates therapeutic benefits in different systems by selectively scavenging free hydroxyl radicals and reactive oxygen species (ROS) (8-10). Inhaled $\mathrm{H}_{2}$ can prevent or reduce pathological or biochemical alterations in cerebral infarction (10), lung graft injury (11), hepatic injury (12), intestinal ischemic injury (13), cisplatin-induced nephrotoxicity (14), cutaneous anaphylaxis (15), general inflammation (16), and asthma (17). Recently, it has been demonstrated that $\mathrm{H}_{2}$-rich saline attenuates allergic inflammation and suppresses the release and activation of eosinophils in $\operatorname{AR}(8,18)$. Mast cells are the key effector cells in the immunoglobulin $\mathrm{E}$ (IgE)-mediated allergic reactions, and $\mathrm{H}_{2}$ can attenuate the high-affinity IgE receptor-mediated signal transduction (15). 
However, to the best of our knowledge, it remains unclear whether $\mathrm{H}_{2}$ induces therapeutic effects in nasal inflammation and whether high concentrations of $\mathrm{H}_{2}$ could be applicable to the treatment of AR.

AR is a chronic inflammatory condition associated with T-helper cell (Th)1/Th2 imbalance. In the present study, the beneficial effects of small molecule gases, $\mathrm{H}_{2}$ and helium $(\mathrm{He})$, were compared in a murine model of AR. The expression levels of Th1/Th2 cytokines in the serum were also studied using a multiplex cytokine assay. The current study demonstrated that inhalation of $\mathrm{H}_{2}$ alleviated nasal allergic inflammation and reversed the weight loss caused by AR in mice.

\section{Materials and methods}

Animals. A total of 106 female BALB/c mice (age, 6-8 weeks; weight, 19-22 g) were purchased from Shanghai Laboratory Animals Center (Shanghai, China) and housed in a temperature-controlled room $\left(23 \pm 2^{\circ} \mathrm{C}\right)$ with $55 \pm 10 \%$ humidity under a 12-h light/dark cycle. The mice had ad libitum access to standard rodent chow and tap water. All of the experimental procedures performed on mice were in accordance with the Guide for the Care and Use of Laboratory Animals of Tongji University and approved by the Ethics Committee of Laboratory Animal Center of Tongji Universtiy (Shanghai, China).

AR model. The murine model of AR was established as described previously with minor modifications (19). Briefly, the mice were sensitized by intraperitoneal injection of $40 \mu \mathrm{g}$ ovalbumin (OVA; grade V; Sigma-Aldrich; Merck $\mathrm{KGaA}$, Darmstadt, Germany) used in conjunction with $2 \mathrm{mg}$ aluminum hydroxide adjuvant diluted in normal saline (NS) on days $0,2,4,6,8,10$ and 12 . Starting on day 13 , the mice were intranasally challenged with $10 \%$ OVA $(10 \mu \mathrm{l} /$ nostril $)$ once a day for 7 consecutive days. The control mice were sensitized with aluminum hydroxide diluted in NS alone and challenged with NS.

Gas inhalation and study groups. Hydrogen gas was produced using the AMS-H-01 hydrogen oxygen nebulizer (Asclepius Meditec Co., Ltd., Shanghai, China), which simultaneously produced oxygen by electrolyzing water (vol/vol: $66.7 \% \mathrm{H}_{2}$ and $33.3 \% \mathrm{O}_{2}$ ). Mice were housed in a standard cage with food and water available ad libitum and the cage was placed in a semi-closed metal box. The cage was supplied with $\mathrm{H}_{2}$ mixture, in which the volume of oxygen was automatically adjusted to $21 \%$ by controlling nitrogen $\left(\mathrm{N}_{2}\right)$ input. The final volume fraction of $\mathrm{H}_{2}$ mixture in the cage was $\sim 40 \% \mathrm{H}_{2}$, $21 \% \mathrm{O}_{2}$, and $39 \% \mathrm{~N}_{2}$. In the inert gas experiments, the mice were subject to He inhalation. These mice were kept in a cage supplied with a He mixture $\left(\mathrm{He} / \mathrm{O}_{2} / \mathrm{N}_{2}: 40 / 21 / 39 \%\right)$.

A total of 60 female BALB/c mice were randomly divided into six groups of 10 mice each, as follows: i) Control group, mice were exposed to ambient atmosphere; ii) control $+\mathrm{H}_{2}$ group, mice inhaled the $\mathrm{H}_{2}$ mixture for 4 h daily for 7 consecutive days before each intranasal NS challenge; iii) control $+\mathrm{He}$ group, mice inhaled the He mixture for $4 \mathrm{~h}$ daily for 7 consecutive days before each intranasal NS challenge; iv) AR group, AR mice were exposed to ambient atmosphere; v) $\mathrm{AR}+\mathrm{H}_{2}$ group, AR mice inhaled the $\mathrm{H}_{2}$ mixture for $4 \mathrm{~h}$ daily for 7 consecutive days before each intranasal OVA challenge; and vi) $\mathrm{AR}+\mathrm{He}$ group, AR mice inhaled the He mixture for $4 \mathrm{~h}$ daily for 7 consecutive days before each intranasal OVA challenge (Fig. 1). The body weight of the mice was measured on days 0,12 and 20.

In dose-effect experiments, 4 control mice were exposed to air and 42 AR mice ( 7 groups; 6 AR mice in each group) were exposed to the $\mathrm{H}_{2}$ mixture for $0,0.5,1$ or $2 \mathrm{~h}$ each time, once or twice a day, for 7 consecutive days.

Assessment of nasal symptoms. The severity of nasal allergic symptoms was determined by measuring the frequencies of sneezing and nose-scratching for $10 \mathrm{~min}$ after the last intranasal OVA/NS challenge. In order to eliminate bias, mice were subjected to an observation in a single-blinded manner by examiners.

Serum multiple cytokine assay. Mice were euthanized with an intraperitoneal overdose of sodium pentobarbital $(100 \mathrm{mg} / \mathrm{kg}$ bodyweight) $24 \mathrm{~h}$ after the last intranasal challenge. Blood was collected from the retro-orbital sinus and centrifuged at $1,000 \times \mathrm{g}$ for $10 \mathrm{~min}$ at $4^{\circ} \mathrm{C}$. Serum was collected and stored at $-80^{\circ} \mathrm{C}$ for cytokine assays. Quantitative assays for multiple cytokines were performed using the commercially available Mouse Cytokine 23-Plex Immunoassay (Bio-Rad Laboratories, Inc., Hercules, CA, USA) according to the manufacturer's protocol. The 23-Plex Immunoassay mainly detects Th1 and Th2 cytokines.

Tissue preparation. Decapitated mouse heads were fixed in $4 \%$ paraformaldehyde for $48 \mathrm{~h}$ at room temperature, decalcified in 10\% EDTA for 4-5 weeks, and embedded in paraffin. The embedded nasal cavities were cut into $4-\mu \mathrm{m}$-thin sections in the coronal direction. The sections were stained in hematoxylin solution for $5 \mathrm{~min}$ and stained in eosin-phloxine solution for $1 \mathrm{~min}$ at room temperature. Images were captured under optical microscopy at x400 magnification.

Statistical analysis. Statistical analyses were performed using SPSS software (version 19.0; IBM Corp., Armonk, NY, USA). All data are presented as the mean \pm standard error of the mean. Statistical analyses of data were performed using one-way analysis of variance followed by Least Significant Difference post hoc test for comparisons among groups. $\mathrm{P}<0.05$ was considered to indicate a statistically significant difference.

\section{Results}

Hydrogen inhalation alleviates nasal allergic symptoms. The murine model of AR established via sensitization and challenge with OVA in the present study, has been previously used to investigate the pathological and physiological mechanisms of AR (19). Allergic symptoms, including sneezing and nasal itching, were assessed based on behavioral observations in mice. The current study examined the effects of $\mathrm{H}_{2}$ or He inhalation on allergic symptoms. As shown in Fig. 2, the numbers of sneezing and nose scratching events within 10 min following the last OVA challenge in the AR group 


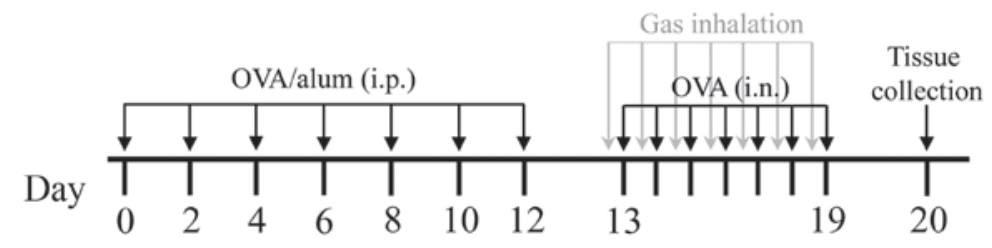

Figure 1. The protocol for the gas inhalation experiments in the murine model of allergic rhinitis. OVA, ovalbumin; alum, aluminum hydroxide; i.p., intraperitoneal injection; i.n., intranasal injection.

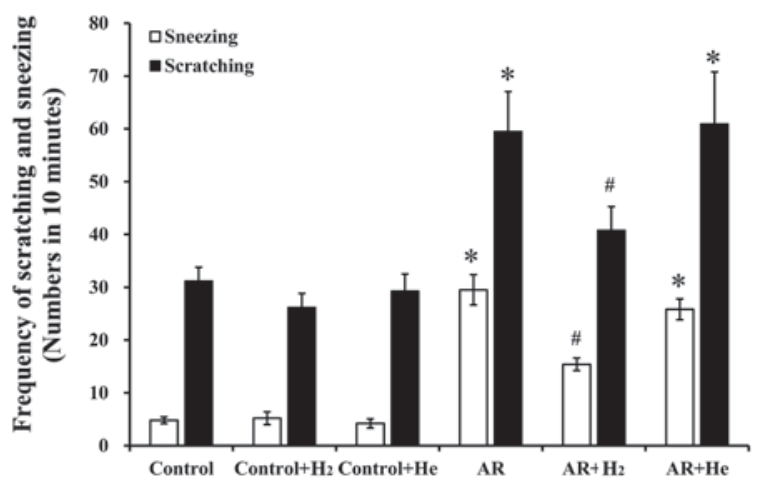

Figure 2. Frequencies of sneezing and nose scratching within $10 \mathrm{~min}$ after the last ovalbumin challenge in mice. Data are presented as the mean \pm standard error of the mean. ${ }^{*} \mathrm{P}<0.001$ vs. the control group, vs. the control $+\mathrm{H}_{2}$ group, and vs the control $+\mathrm{He}$ group; ${ }^{*} \mathrm{P}<0.05$ vs. the $\mathrm{AR}$ group. $\mathrm{H}_{2}$, hydrogen gas; $\mathrm{He}$, helium gas; AR, allergic rhinitis.

(29.5 \pm 2.9 and 59.5 \pm 7.6 , respectively) significantly increased compared with the control group $(4.8 \pm 0.6$ and $31.2 \pm 2.6$, respectively, $\mathrm{P}<0.001)$, the control $+\mathrm{H}_{2}$ group (5.2 \pm 1.2 and $26.2 \pm 2.6$, respectively, $\mathrm{P}<0.001)$, and the control + He group (4.2 \pm 0.9 and $29.3 \pm 3.2$, respectively, $\mathrm{P}<0.001)$. In the $\mathrm{AR}+\mathrm{H}_{2}$ group, the frequencies of sneezing and scratching $(15.4 \pm 1.2$ and 40.8 $\pm 4.5 / 10 \mathrm{~min}$, respectively) decreased significantly compared with the AR group $(\mathrm{P}<0.001$ and $\mathrm{P}=0.025$, respectively). He inhalation did not markedly alter the frequencies of sneezing and nasal itching in the AR+He group compared with the AR group $(25.8 \pm 1.9$ and $60.9 \pm 9.8 / 10 \mathrm{~min} ; \mathrm{P}=0.117$ and $\mathrm{P}=0.864$, respectively). Additionally, $\mathrm{H}_{2}$ and $\mathrm{He}$ inhalation pretreatment in the control mice exhibited no significant effects on nasal symptoms compared with the control group. These results indicate that $\mathrm{H}_{2}$ inhalation, rather than $\mathrm{He}$, could alleviate nasal allergic symptoms in OVA-challenged mice.

$\mathrm{H}_{2}$ inhalation inhibits allergic inflammation of nasal mucosa. Sensitization and challenge with OVA can induce significant allergic inflammation in mouse nasal mucosa (Fig. 3A). The ciliated epithelium was damaged and discontinuous in the AR group (Fig. 3B). Numerous inflammatory cells, including lymphocytes and eosinophils, were observed in the submucosa. In the $\mathrm{AR}+\mathrm{H}_{2}$ group, the elevated infiltration of inflammatory cells into the mucosa and submucosa was inhibited compared with the AR group (Fig. 3D), and the integrity of the mucosa was protected. No apparent difference was observed between the AR and AR + He groups (Fig. 3B and F). These results indicate that $\mathrm{H}_{2}$ inhalation pretreatment could reduce the inflammatory injury of nasal mucosa.

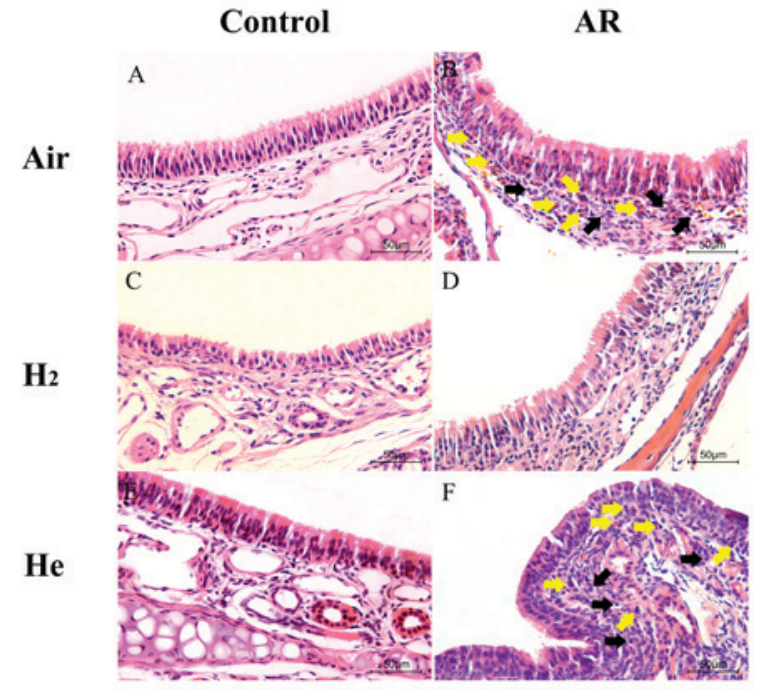

Figure 3. Effect of hydrogen inhalation on nasal mucosa inflammation. Representative sections of the nasal tissues (original magnification, $\mathrm{x} 400$ ) after hematoxylin and eosin staining. (A) The control group. (B) The AR group. (C) The control $+\mathrm{H}_{2}$ group. (D) The $\mathrm{AR}+\mathrm{H}_{2}$ group. (E) The control + He group. (F) The AR + He group. Yellow arrows indicate eosinophils; black arrows indicate lymphocytes. $\mathrm{H}_{2}$, hydrogen gas; He, helium gas; AR, allergic rhinitis.

Hydrogen inhalation decreases cytokine and chemokine levels in serum. Th2 cytokines, interleukin (IL)-4, -5 and -13, serve roles in airway allergic inflammation, including AR and asthma (18). The present study investigated the effects of $\mathrm{H}_{2}$ inhalation on the expression of several cytokines and chemokines in serum using the Cytokine 23-Plex Immunoassay. Expression levels of IL-5, IL-13 and monocyte chemoattractant protein-1 (MCP-1) were significantly increased in the AR group compared with the control. $\mathrm{H}_{2}$ inhalation significantly decreased the expression levels of these cytokines and chemokines (Fig. 4A-C). Th1/Th2 immunological imbalance is involved in the pathophysiological process of allergic inflammation (18). The expression level of interferon- $\gamma$ (IFN- $\gamma$ ), a Th1 cytokine, decreased in the AR group compared with the control, and $\mathrm{H}_{2}$ inhalation increased the level of IFN- $\gamma$; however, these differences were not statistically significant. Furthermore, no significant difference was found between the $\mathrm{AR}$ and $\mathrm{AR}+\mathrm{H}_{2}$ groups (Fig. 4D).

Dose-effect of $\mathrm{H}_{2}$ inhalation on AR. To investigate the dose-effect association between $\mathrm{H}_{2}$ inhalation and allergic symptoms, different inhalation frequencies and durations were used in the murine models of AR. The frequency of sneezing decreased following administration of $\mathrm{H}_{2}$ in a dose-dependent 
A

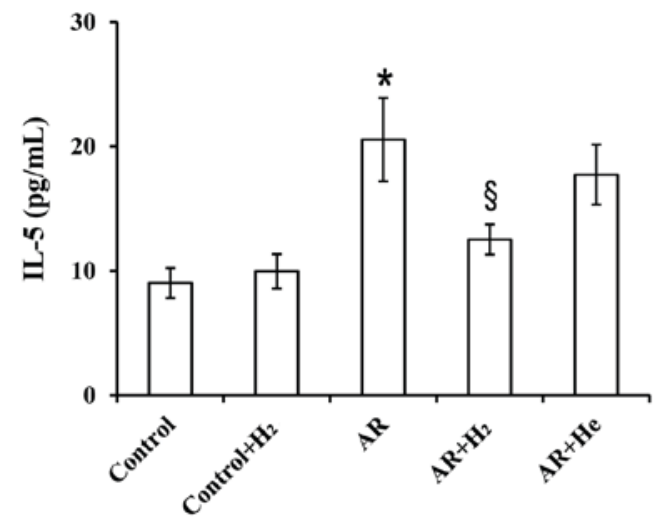

$\mathrm{C}$

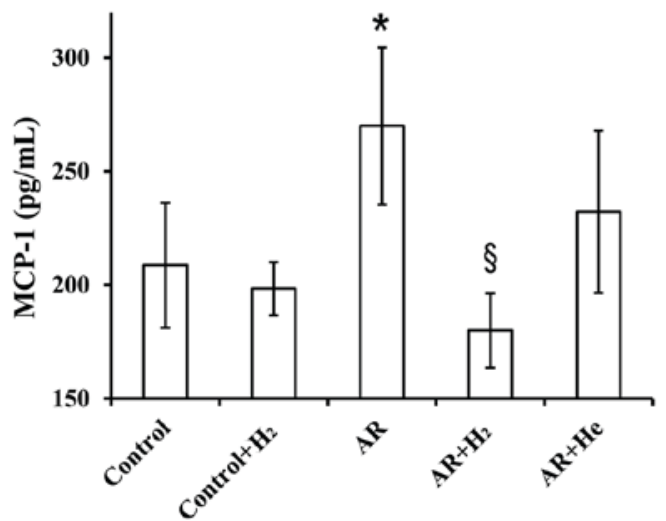

$\mathrm{B}$

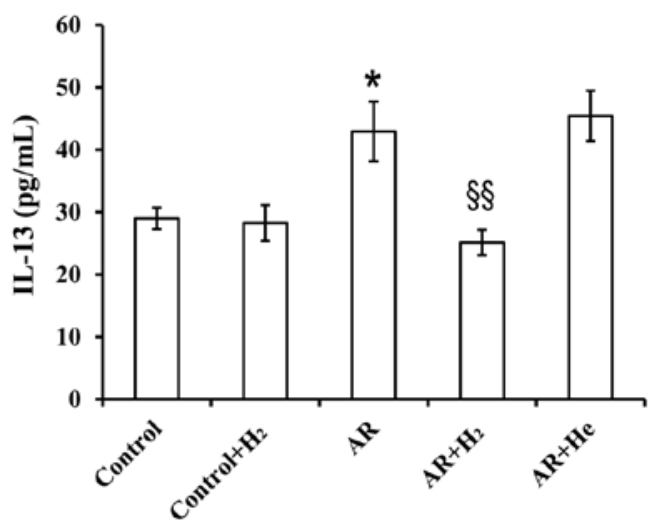

D

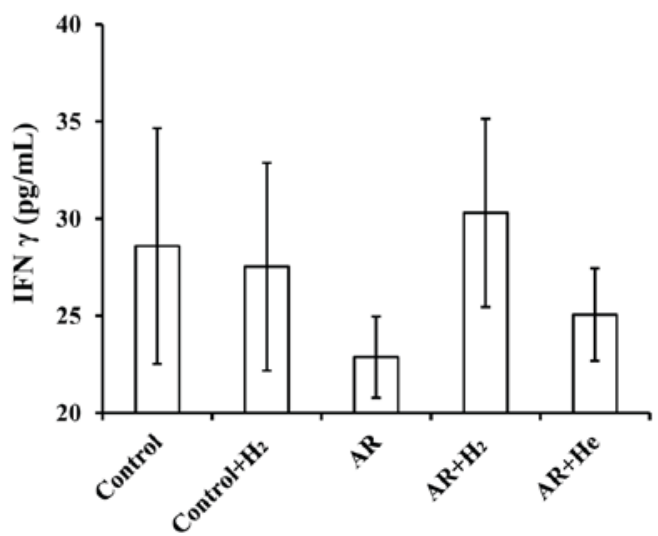

Figure 4. Effect of hydrogen inhalation on serum expression of cytokines and chemokines. The expression of (A) IL-5, (B) IL-13, (C) MCP-1 and (D) IFN- $\gamma$. Data are presented as the mean \pm standard error of the mean. ${ }^{*} \mathrm{P}<0.05$ vs. the control group; ${ }^{\circledR} \mathrm{P}<0.05$ and ${ }^{\$ \S} \mathrm{P}<0.01$ vs. the AR group. $\mathrm{H}_{2}$, hydrogen gas; $\mathrm{He}$, helium gas; AR, allergic rhinitis; IL, interleukin; MCP-1, monocyte chemoattractant protein-1; IFN- $\gamma$, interferon- $\gamma$.

A

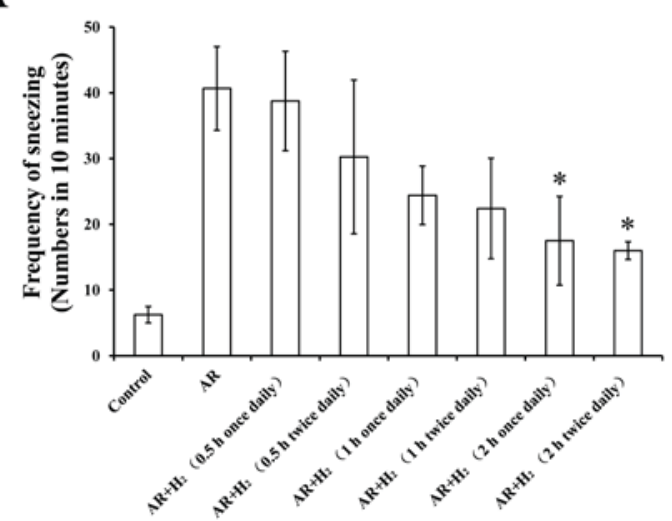

B

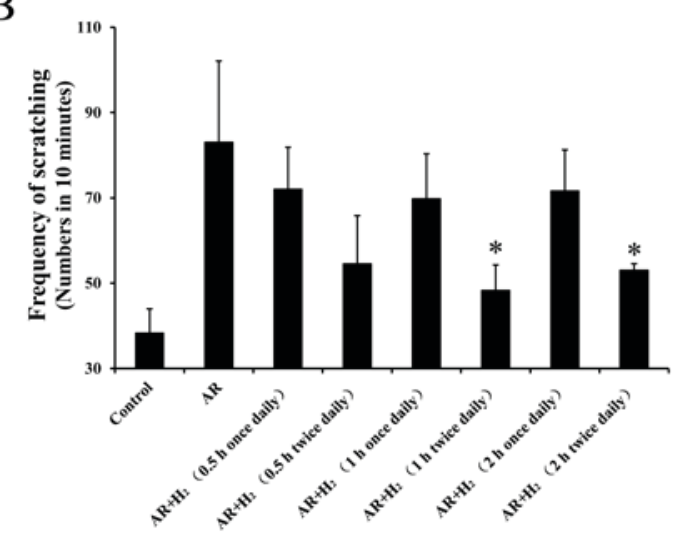

Figure 5. Effect of different $\mathrm{H}_{2}$ inhalation frequencies and durations on nasal allergic symptoms. Mice were exposed to the $\mathrm{H}_{2}$ mixture for 0.5 , 1 or $2 \mathrm{~h}$ each time, once or twice a day. The effects on (A) sneezing and (B) scratching. Data are presented as the mean \pm standard error of the mean. ${ }^{*} \mathrm{P}<0.05 \mathrm{vs}$. the AR group. $\mathrm{H}_{2}$, hydrogen gas; $\mathrm{He}$, helium gas; AR, allergic rhinitis.

manner (Fig. 5A). The frequencies of sneezing following 2-h exposure once a day (17.5 $\pm 6.7 / 10 \mathrm{~min})$ and 2-h exposure twice a day $(16 \pm 1.4 / 10 \mathrm{~min})$ significantly decreased compared with the AR group (40.7 $\pm 6.4 / 10$ min; $\mathrm{P}=0.037$ and $\mathrm{P}=0.027$, respectively). Frequencies of scratching were lower in the twice daily $\mathrm{H}_{2}$ administration groups compared with once daily $\mathrm{H}_{2}$ administration groups, regardless of the duration of inhalation
(Fig. 5B). While, only the frequencies of scratching following a 1 and 2-h exposure twice a day $(48.3 \pm 6.0$ and $53.0 \pm 1.5 / 10 \mathrm{~min}$, respectively) were significantly decreased compared with the AR group $(83.0 \pm 19.1 / 10 \mathrm{~min} ; \mathrm{P}=0.028$ and $\mathrm{P}=0.045$, respectively). These results indicated that $\mathrm{H}_{2}$ inhalation for $2 \mathrm{~h}$ twice a day exhibited a significant therapeutic effect on AR in the mouse models used in the present study. 
$\mathrm{H}_{2}$ inhalation regulates mice weight. Our earlier work indicated that AR could limit the increase in mice body weight (data not published). In the present study, the baseline weight in all groups was comparable. During the modeling phase, there was no significant difference in weight gain between mice after OVA-sensation or OVA-challenge alone, compared with the control (Tables I and II, respectively). After the model had been successfully established, the weight gain in the AR group was $0.95 \pm 0.20 \mathrm{~g}$, which was lower than in the control group (1.57 $\pm 0.41 \mathrm{~g} ; \mathrm{P}=0.081$; Table III). Furthermore, reduced food intake behavior was observed in AR mice (data not shown). The hair of mice in the AR group were disordered with a lack of luster. Similarly, no significant differences were observed for weight gain in the control $+\mathrm{H}_{2}$ group compared with the $\mathrm{AR}+\mathrm{H}_{2}$ group, and the control $+\mathrm{He}$ group compared with the $\mathrm{AR}+\mathrm{He}$ group (Table III). Hydrogen inhalation increased the bodyweight in AR mice by $0.36 \pm 0.12 \mathrm{~g}$ (Table III). Although no statistically significant difference in weight gain was identified compared with the control $+\mathrm{H}_{2}$ group $(-0.10 \pm 0.30 \mathrm{~g}$; $\mathrm{P}=0.293)$, AR mice with $\mathrm{H}_{2}$ exposure appeared more active. He inhalation did not improve the weight loss in AR mice $(-0.38 \pm 0.14 \mathrm{~g})$ compared with the control group $(0.57 \pm 0.17 \mathrm{~g}$; Table III).

The weight gain in the control $+\mathrm{H}_{2}$ group $(-0.46 \pm 0.15 \mathrm{~g})$ was significantly lower compared with the control group $(0.57 \pm 0.17 \mathrm{~g} ; \mathrm{P}=0.001)$. Mice in the control + He group exhibited a $0.18 \pm 0.14 \mathrm{~g}$ weight gain which was not significantly different compared with the weight gain in the control group $\left(\mathrm{P}=0.161\right.$; Table IV). Mice in the $\mathrm{AR}+\mathrm{H}_{2}$ group exhibited a $0.60 \pm 0.21 \mathrm{~g}$ weight gain, which was significantly higher compared with the weight gain in the AR group $(0.23 \pm 0.24 \mathrm{~g}$; $\mathrm{P}=0.008)$. He inhalation did not improve the weight gain in mouse models of AR. These results indicated that $\mathrm{H}_{2}$ inhalation can restrain weight increase in healthy mice and reverse weight loss induced by AR.

\section{Discussion}

$\mathrm{H}_{2}$ is a medical gas with antioxidative, anti-inflammatory and antiapoptotic properties $(6,8,16,20)$. Previous studies have indicated that a low concentration of $\mathrm{H}_{2}$ can be used in a number of diseases $(9,11-14,20)$. Both inhalation of low-concentration $\mathrm{H}_{2}(1-4 \%)$ and administration of $\mathrm{H}_{2}$-rich saline are effective treatment methods $(18,21,22)$. Water electrolysis is a feasible and convenient $\mathrm{H}_{2}$ source for large-scale clinical use. In the current study, the concentration of $\mathrm{H}_{2}$ produced by electrolyzing water was markedly higher compared with the concentration used in previous studies (11-17). No mice succumbed during the observation period, thus the present study demonstrated that a high concentration of $\mathrm{H}_{2}$ can safely and efficiently ameliorate OVA-induced nasal allergy symptoms in a mouse model of AR.

Oxidant/antioxidant imbalance serves an important role in airway inflammation $(23,24)$. Oxidative stress and ROS contribute to allergic inflammation (6-8). Inflammatory cells, including eosinophils, neutrophils and lymphocytes from the airway/blood, have been demonstrated to produce oxidants in response to various stimuli $(23,25)$. Oxidative stress and ROS can disrupt the integrity and function of epithelial cilia and alter the expression of adhesion molecules, resulting in an osmotic
Table I. Effect of ovalbumin-sensitization on the bodyweight of mice.

\begin{tabular}{lcc}
\hline Group & Weight gain $(\mathrm{g})$ & P-value \\
\hline Non-sensitized & $0.58 \pm 0.12$ & 0.078 \\
Sensitized & $0.93 \pm 0.15$ & \\
\hline
\end{tabular}

Weight gain=bodyweight after sensitization-initial bodyweight.

Table II. Effect of ovalbumin-challenge on the bodyweight of mice.

\begin{tabular}{lrc}
\hline Group & Weight gain $(\mathrm{g})$ & P-value \\
\hline Control & $0.57 \pm 0.17$ & 0.264 \\
$\mathrm{AR}$ & $0.23 \pm 0.24$ & \\
$\mathrm{Control}+\mathrm{H}_{2}$ & $-0.46 \pm 0.15$ & 0.644 \\
$\mathrm{AR}+\mathrm{H}_{2}$ & $0.60 \pm 0.21$ & \\
Control $+\mathrm{He}$ & $0.18 \pm 0.14$ & 0.102 \\
$\mathrm{AR}+\mathrm{He}$ & $-0.73 \pm 0.32$ & \\
\hline
\end{tabular}

Weight gain=bodyweight after challenge-bodyweight before challenge. $\mathrm{H}_{2}$, hydrogen gas; He, helium gas; $\mathrm{AR}$, allergic rhinitis.

Table III. Effect of AR on the bodyweight of mice.

\begin{tabular}{lcc}
\hline Group & Weight gain $(\mathrm{g})$ & P-value \\
\hline Control & $1.57 \pm 0.41$ & 0.081 \\
$\mathrm{AR}$ & $0.95 \pm 0.20$ & \\
$\mathrm{Control}+\mathrm{H}_{2}$ & $-0.10 \pm 0.30$ & 0.293 \\
$\mathrm{AR}+\mathrm{H}_{2}$ & $0.36 \pm 0.12$ & \\
Control $+\mathrm{He}$ & $0.57 \pm 0.17$ & 0.560 \\
$\mathrm{AR}+\mathrm{He}$ & $-0.38 \pm 0.14$ &
\end{tabular}

Weight gain=bodyweight after challenge-initial bodyweight. $\mathrm{H}_{2}$, hydrogen gas; He, helium gas; AR, allergic rhinitis.

increase in mucosa and mucus production (8). Eosinophils and mast cells are the main effector cell populations of allergic airway inflammation. Antigen challenge improves the release of ROS from eosinophils in the airway and blood of patients with asthma $(26,27) . \mathrm{H}_{2}$-rich saline can suppress active eosinophils by decreasing serum levels of eosinophil cationic protein in AR (8). In the current study, inhalation of high concentrations of $\mathrm{H}_{2}(40 \%)$ decreased the infiltration of the mucosa and submucosa by inflammatory cells including eosinophils and lymphocytes, and the damaged and discontinuous ciliated epithelium was effectively protected by treatment with $\mathrm{H}_{2}$. Zhang et al (17) demonstrated that inhalation of $67 \% \mathrm{H}_{2}$ markedly improved the lung function and protected the airway inflammation in an asthmatic murine model. In their experimental settings, the concentrations of inhaled $\mathrm{O}_{2}$ was $33 \%$ (17). 
Table IV. Effect of $\mathrm{H}_{2}$ inhalation on the bodyweight of mice.

\begin{tabular}{lcc}
\hline Group & Weight gain $(\mathrm{g})$ & P-value \\
\hline Control & $0.57 \pm 0.17$ & \\
Control $+\mathrm{H}_{2}$ & $-0.46 \pm 0.15$ & $0.001^{\mathrm{a}}$ \\
Control $+\mathrm{He}$ & $0.18 \pm 0.14$ & $0.161^{\mathrm{a}}$ \\
$\mathrm{AR}$ & $0.23 \pm 0.24$ & \\
$\mathrm{AR}+\mathrm{H}_{2}$ & $0.60 \pm 0.21$ & $0.008^{\mathrm{b}}$ \\
$\mathrm{AR}+\mathrm{He}$ & $-0.73 \pm 0.32$ & $0.002^{\mathrm{b}}$ \\
\hline
\end{tabular}

Weight gain=bodyweight after gas inhalation-bodyweight before gas inhalation. ${ }^{\mathrm{a}}$ vs. Control group; ${ }^{\mathrm{b}}$ vs. AR group. $\mathrm{H}_{2}$, hydrogen gas; He, helium gas; AR, allergic rhinitis.

In the present study, the concentration of oxygen inhaled by mice was $21 \%$, the same as that in the ambient atmosphere. This method excluded the effect of high concentration oxygen on mice. The current data revealed that a high concentration of $\mathrm{H}_{2}$ from water electrolysis may exhibit a therapeutic effect on AR.

The immune dysfunction resulting from the Th1/Th2 response imbalance is a major cause of chronic allergic inflammation, including AR $(18,19)$. Th2 cells and Th2 cytokines serve an important role in the pathophysiology of AR $(28,29)$, and the allergic symptoms can be controlled by inhibiting Th2 responses. Th2 cytokines, including IL-5 and IL-13, are involved in multiple steps in the lifecycle of eosinophils (18). IL-5 promotes the differentiation and maturation of eosinophil progenitors, stimulates cell migration, induces cytokine synthesis and degranulation, enhances production of oxygen radicals and leukotrienes, and promotes and prolongs the survival of eosinophils (30). IL-13 serves a role in airway hypersensitivity and mucus hypersecretion (18). It acts on B cells to produce IgE by activating eosinophils and basophils (18). The current study indicated that the levels of IL-5 and -13 were significantly decreased in the serum of the $\mathrm{AR}+\mathrm{H}_{2}$ group compared with the AR group. These results are consistent with previous research $(17,18)$ and reveal that high concentrations of inhaled $\mathrm{H}_{2}$ could markedly decrease the levels of Th2 cytokines and inhibit Th2 responses in allergic diseases. IFN- $\gamma$ is one of the major Th1 cytokines, which promotes the differentiation of Th0 cells to Th1 and inhibits the generation of Th2 cells by inducing T-bet expression (31). In our previous study, a decreased level of IFN- $\gamma$ was observed in the nasal cavity lavage fluid from AR mice (31). In the present study, the level of IFN- $\gamma$ in serum was slightly decreased in the AR group mice compared with the control group. However, $\mathrm{H}_{2}$ inhalation reversed the decreased level of IFN- $\gamma$ in the AR $+\mathrm{H}_{2}$ group. Although $\mathrm{H}_{2}$ inhalation had no statistically significant influence on IFN- $\gamma$ expression, the significantly decreased levels of IL-5 and -13 and slightly increased IFN- $\gamma$ levels indicated that $\mathrm{H}_{2}$ may serve a role in the regulation of the Th1/Th2 immune responses. MCP-1 is a small cytokine primarily secreted by monocytes, macrophages and dendritic cells. MCP-1 recruits monocytes, $\mathrm{T}$ cells and dendritic cells to the sites of inflammation resulting from tissue injury, antigens or infection. $\mathrm{H}_{2}$ inhalation was demonstrated to significantly reverse the increased MCP-1 expression level in AR mice, reducing the inflammation in the later stage of AR.

Previous results concerning the effects of allergic inflammation on body weight are inconsistent. Loerbroks et al (32) reported that the prevalence of asthma among obese women was almost twice as high as among normal weight women, and a causal relationship between asthma and incident weight gain cannot be excluded. In an animal model study, Hong et al (33) observed that normal group mice exhibited increased weight compared with AR mice. The current study indicated that food intake was decreased and that weight increase was lower in AR group mice. However, $\mathrm{H}_{2}$ inhalation differentially regulated the body weight in different groups of mice. For normal mice, $\mathrm{H}_{2}$ inhalation inhibited the weight gain. In AR mice, $\mathrm{H}_{2}$ inhalation promoted weight increase.

There are certain limitations in the current study. The study only presented results for certain cytokines which expression levels between groups were statistically significantly different. Oxidative stress serves an important role in the pathogenesis of allergic diseases and $\mathrm{H}_{2}$ can selectively reduce the levels of $\operatorname{ROS}(9,12,13,17) . \mathrm{H}_{2}$ can significantly increase the expression of nuclear factor erythroid 2-related factor 2 (Nrf2) in epithelial cells and Nrf2 is the key molecule of antioxidative stress of hydrogen $(34,35)$. Therefore, future studies are required to determine the effects of $\mathrm{H}_{2}$ on the Nrf2 signaling pathway in the nasal epithelial cells of AR.

In conclusion, $\mathrm{H}_{2}$ inhalation at a high concentration may improve nasal allergic symptoms, reduce inflammatory cell infiltration in nasal mucosa, and regulate Th1/Th2 responses. The inhibitory effect of $\mathrm{H}_{2}$ inhalation on nasal allergic symptoms over a long period is more effective than that over a short period. At an equal inspiratory volume, multiple inhalation events result in greater improvements compared with single inhalation events. In addition, treatment with $\mathrm{H}_{2}$ exhibited a beneficial effect on mouse health through selective weight control. The present study indicated that $\mathrm{H}_{2}$ may have a therapeutic value for allergic diseases.

\section{Acknowledgements}

Not applicable.

\section{Funding}

The present study was supported by National Natural Science Foundation of China (cat. no. 81300809) and Shanghai Pudong New Area Science \& Technology Development Fund (cat. nos. PKJ2016-Y02 and PW2016D-11).

\section{Availability of data and materials}

The datasets of the present study are available from the corresponding authors.

\section{Authors' contributions}

SF, XL, XW, YZ, and ZM were responsible for performance of experiment, and data analysis. YW and WW were responsible for manuscript writing and revision, and experimental design. 


\section{Ethics approval and consent to participate}

The experiment protocols were approved by the Ethics Committee of Laboratory Animal Center of Tongji Universtiy (Shanghai, China; approval no: TJLAC-017-028).

\section{Patient consent for publication}

Not applicable.

\section{Competing interests}

The authors declare that they have no competing interests.

\section{References}

1. Bousquet J, Jacot W, Vignola AM, Bachert C and Van Cauwenberge P: Allergic rhinitis: A disease remodeling the upper airways? J Allergy Clin Immunol 113: 43-49, 2004.

2. Warner JO: Allergic rhinitis is an extremely common problem, but prevalence rates widely vary between countries. Pediatr Allergy Immunol 21: e105-e106, 2010.

3. Zhang L, Han D, Huang D, Wu Y, Dong Z, Xu G, Kong W and Bachert C: Prevalence of self-reported allergic rhinitis in eleven major cities in China. Int Arch Allergy Immunol 149: 47-57, 2009.

4. Zhang Y and Zhang L: Prevalence of allergic rhinitis in china. Allergy Asthma Immunol Res 6: 105-113, 2014.

5. Cheng L, Chen J, Fu Q, He S, Li H, Liu Z, Tan G, Tao Z, Wang D, Wen $\mathrm{W}$, et al: Chinese society of allergy guidelines for diagnosis and treatment of allergic rhinitis. Allergy Asthma Immunol Res 10: 300-353, 2018.

6. Sim CS, Lee JH, Kim SH, Han MW, Kim Y, Oh I, Yun SC and Lee JC: Oxidative stress in schoolchildren with allergic rhinitis: Propensity score matching case-control study. Ann Allergy Asthma Immunol 115: 391-395, 2015.

7. Sagdic A, Sener O, Bulucu F, Karadurmus N, Özel HE, Yamanel L, Tasci C, Naharci I, Ocal R and Aydin A: Oxidative stress status and plasma trace elements in patients with asthma or allergic rhinitis. Allergol Immunopathol (Madr) 39: 200-205, 2011.

8. Yu S, Zhao C, Che N, Jing L and Ge R: Hydrogen-rich saline attenuates eosinophil activation in a guinea pig model of allergic rhinitis via reducing oxidative stress. J Inflamm (Lond) 14: 1, 2017.

9. Ohsawa I, Ishikawa M, Takahashi K, Watanabe M, Nishimaki K, Yamagata K, Katsura K, Katayama Y, Asoh S and Ohta S: Hydrogen acts as a therapeutic antioxidant by selectively reducing cytotoxic oxygen radicals. Nat Med 13 688-694, 2007.

10. Sato Y, Kajiyama S, Amano A, Kondo Y, Sasaki T, Handa S, Takahashi R, Fukui M, Hasegawa G, Nakamura N, et al: Hydrogen-rich pure water prevents superoxide formation in brain slices of vitamin C-depleted SMP30/GNL knockout mice. Biochem Biophys Res Commun 375: 346-350, 2008.

11. Zhou H, Fu Z, Wei Y, Liu J, Cui X, Yang W, Ding W, Pan P and Li W: Hydrogen inhalation decreases lung graft injury in brain-dead donor rats. J Heart Lung Transplant 32: 251-258, 2013.

12. Fukuda K, Asoh S, Ishikawa M, Yamamoto Y, Ohsawa I and Ohta S: Inhalation of hydrogen gas suppresses hepatic injury caused by ischemia/reperfusion through reducing oxidative stress. Biochem Biophys Res Commun 361: 670-674, 2007.

13. Buchholz BM, Kaczorowski DJ, Sugimoto R, Yang R, Wang Y, Billiar TR, McCurry KR, Bauer AJ and Nakao A: Hydrogen inhalation ameliorates oxidative stress in transplantation induced intestinal graft injury. Am J Transplant 8: 2015-2024, 2008.

14. Nakashima-Kamimura N, Mori T, Ohsawa I, Asoh S and Ohta S: Molecular hydrogen alleviates nephrotoxicity induced by an anti-cancer drug cisplatin without compromising anti-tumor activity in mice. Cancer Chemother Pharmacol 64: 753-761, 2009.

15. Itoh T, Fujita Y, Ito M, Masuda A, Ohno K, Ichihara M, Kojima T, Nozawa Y and Ito M: Molecular hydrogen suppresses FcepsilonRI-mediated signal transduction and prevents degranulation of mast cells. Biochem Biophys Res Commun 389: 651-656, 2009
16. Xie K, Yu Y, Zhang Z, Liu W, Pei Y, Xiong L, Hou L and Wang G: Hydrogen gas improves survival rate and organ damage in zymosan-induced generalized inflammation model. Shock 34: 495-501, 2010.

17. Zhang N, Deng C, Zhang X, Zhang J and Bai C: Inhalation of hydrogen gas attenuates airway inflammation and oxidative stress in allergic asthmatic mice. Asthma Res Pract 4: 3, 2018.

18. Zhao C, Yu S, Li J, Xu W and Ge R: Changes in IL-4 and IL-13 expression in allergic-rhinitis treated with hydrogen-rich saline in guinea-pig model. Allergol Immunopathol (Madr) 45: 350-355, 2017.

19. Wang W, Jiang T, Zhu Z, Cui J, Zhu L and Ma Z: Dexamethasone suppresses allergic rhinitis and amplifies CD4(+) Foxp3(+) regulatory T cells in vitro. Int Forum Allergy Rhinol 5: 900-906, 2015.

20. Diao M, Zhang S, Wu L, Huan L, Huang F, Cui Y and Lin Z: Hydrogen gas inhalation attenuates seawater instillation-induced acute lung injury via the Nrf2 pathway in rabbits. Inflammation 39: 2029-2039, 2016

21. Cui J, Chen X, Zhai X, Shi D, Zhang R, Zhi X, Li X, Gu Z, Cao L, Weng W, et al: Inhalation of water electrolysis-derived hydrogen ameliorates cerebral ischemia-reperfusion injury in rats-a possible new hydrogen resource for clinical use. Neuroscience 335: 232-241, 2016.

22. Xin Y, Liu H, Zhang P, Chang L and Xie K: Molecular hydrogen inhalation attenuates postoperative cognitive impairment in rats. Neuroreport 28: 694-700, 2017.

23. Al-Harbi NO, Nadeem A, Al-Harbi MM, Imam F, Al-Shabanah OA, Ahmad SF, Sayed-Ahmed MM and Bahashwan SA: Oxidative airway inflammation leads to systemic and vascular oxidative stress in a murine model of allergic asthma. Int Immunopharmacol 26: 237-245, 2015.

24. Campos D, Ravagnani FG, Gurgueira SA, Vercesi AE, Teixeira SA, Costa SKP, Muscará MN and Ferreira HHA: Increased glutathione levels contribute to the beneficial effects of hydrogen sulfide and inducible nitric oxide inhibition in allergic lung inflammation. Int Immunopharmacol 39: 57-62, 2016.

25. Sutcliffe A, Hollins F, Gomez E, Saunders R, Doe C, Cooke M, Challiss RA and Brightling CE: Increased nicotinamide adenine dinucleotide phosphate oxidase 4 expression mediates intrinsic airway smooth muscle hypercontractility in asthma. Am J Respir Crit Care Med 185: 267-274, 2012.

26. Calhoun WJ, Reed HE, Moest DR and Stevens CA: Enhanced superoxide production by alveolar macrophages and air-space cells, airway inflammation, and alveolar macrophage density changes after segmental antigen bronchoprovocation in allergic subjects. Am Rev Respir Dis 145: 317-325, 1992.

27. Vachier I, Chanez P, Le Doucen C, Damon M, Descomps B and Godard P: Enhancement of reactive oxygen species formation in stable and unstable asthmatic patients. Eur Respir J 7: 1585-1592, 1994.

28. Ryan MW: Asthma and rhinitis: Comorbidities. Otolaryngol Clin North Am 41: 283-295, vi, 2008.

29. Broide DH: Immunomodulation of allergic disease. Annu Rev Med 60: 279-291, 2009.

30. Hamelmann E and Gelfand EW: IL-5-induced airway eosinophilia-the key to asthma? Immunol Rev 179: 182-191, 2001.

31. Wang W, Zhu Z, Zhu B and Ma Z: Peroxisome proliferator-activated receptor-gamma agonist induces regulatory $\mathrm{T}$ cells in a murine model of allergic rhinitis. Otolaryngol Head Neck Surg 144: 506-513, 2011.

32. Loerbroks A, Apfelbacher CJ, Amelang M and Stürmer T: Obesity and adult asthma: Potential effect modification by gender, but not by hay fever. Ann Epidemiol 18: 283-289, 2008.

33. Hong SH, Kim SR, Choi HS, Ku JM, Seo HS, Shin YC and Ko SG: Effects of Hyeonggaeyeongyo-tang in ovalbumin-induced allergic rhinitis model. Mediators Inflamm 2014: 418705, 2014.

34. Rangasamy T, Cho CY, Thimmulappa RK, Zhen L, Srisuma SS Kensler TW, Yamamoto M, Petrache I, Tuder RM and Biswal S: Genetic ablation of Nrf2 enhances susceptibility to cigarette smoke-induced emphysema in mice. J Clin Invest 114: 1248-1259, 2004.

35. Liu L, Xie K, Chen H, Dong X, Li Y, Yu Y, Wang G and Yu Y: Inhalation of hydrogen gas attenuates brain injury in mice with cecal ligation and puncture via inhibiting neuroinflammation, oxidative stress and neuronal apoptosis. Brain Res 1589: 78-92, 2014.

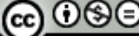

This work is licensed under a Creative Commons Attribution-NonCommercial-NoDerivatives 4.0 International (CC BY-NC-ND 4.0) License. 